Поповичева М.

\title{
Новые направления по заживлению ран
}

Высшая школа здравоохранения и социальной работы св. Елизаветы, Братислава, н.о. Филиал бл. Метода Доминика Трчку, Словакия

maria.popovic911@gmail.com

Поповічева М.

Нові тенденції в загоснні ран

Вища школа охорони здоров'я та соціальної роботи св. Алжбети, Братислава, Н.О. Філія бл. Методу

Домініка Трічку, Словаччина
Popovičová $\mathrm{M}$.

New trends in wound healing

St. Elizabeth University of Health and Social Sciences,

Bratislava - teacher, Field office in Michalovce a Prešov

\section{Введение}

В современное время пролежням уделяется большее внимание, чем когда-либо, со стороны медицины или ухода за больными. Организация ухода за больными с пролежнями сегодня на высокоспециализированном и мультидисциплинарном уровне, где мы встречаемся с понятиями "woundcare“, „woundhealing“, „wound management". Декубиты (пролежни) являются самым серьезным осложнением в медицине. Появление и количество пролежней считается отражением качества ухода за больным. Лечение пролежней не только дорогостоящее, но тут необходима помощь и взаимодействие близких, семьи, пациента, а главное, профессиональное отношение персонала [1]. Обследование декубитов и возможности их лечения на протяжении развития медицины и ухода за больными прошло огромным развитием. Сейчас существует много специальных материалов, техник и правил, которые комплексно решают проблематику декубитов, но первоочередным является принцип индивидуальности. C началом двадцатого века появились новые виды материалов в лечении декубитов.Но и вопреки тому, что спектр этих материалов на рынке очень широк и их доступность большая, ещё существуют стереотипы из прошлого, традиционные методы лечения.

\section{Действия сестры по уходу в профилактике декубитов}

Сестра по уходу как член мультидисциплинарного коллектива, которая имеет при лечении пролежней важную роль, должна обладать адекватной информацией о современных возможностях в лечении декубитов, знать возможности их использования и уметь правильно организовывать работу с пациентом в контексте медицинских принципов по уходу. Использование следующей практики сестрой в профилактике пролежней:

- Контроль и застилание постели пациента (соответствующий матрас, использование антидекубитар- ного матраса, чистое, сухое постельное белье, с поддержкой части головы максимально до $30^{\circ}$ )

- Использование

антидекубитарных приспособлений (использование специальных колец, валиков, подушек с наполнителями, гелевые охранные приспособления, а также приспособления, снижающие давление на определенные части тела).

$$
\text { - Требования к антидекубитарным }
$$

приспособлениям (не ограничивать пациента в движении, они не должны раздражать кожу, легко используемые, воздушные, равномерно распределяющие давление на постели).

- Поворачивание пациента на постели (минимум раз в два часа в течение дня и раз в три часа ночью) [2].

- Забота о коже пациента (уход за состоянием кожи, реализация массажа с массированием пораженных мест только в случае, если кожа без следов покраснения и повреждения).

- Гигиенический уход (к гигиеническому уходу относим гигиенические гели и пены, поддерживающие гидратацию кожи, ограничение использования мыла, которое высушивает кожу).

- Уход при инконтиненции мочи и кала (уход за интимной гигиеной, нахождение подходящих приспособлений, употребление сухого и чистого личного и постельного белья).

- Уход за общим состоянием пациента (поддержка мобильности, навыков самообслуживания, активизация, реализация пассивных и активных упражнеинй в постели).

В контексте комплексного подхода к лечению декубитов важна не только самостоятельная техника или метод лечения пролежней, но большое значение имеет сотрудничество в рамках коллектива, мобилизация, гидратация и обеспечение адекватного питания пациента. Важно избежать дальнейшие компликации в связи с возникновением пролежня и решать состояние пациента глобально [3]. В лечении пролежней приоритетным является элиминация давления, трения и профилактика 
инфекции. При выборе метода лечения и правильного материала решающим является рациональный выбор по типу, обширности, локализации и глубине пролежня. Составляющей общего лечения пациента с пролежнем может быть обеспечение адекватного питания, гидратации, уменьшения боли и адекватное лечение основного заболевания [4,5].

\section{Современные направления по лечению декубитов}

Лечение ран прошло огромное развитие через использование традиционных правил и традиционных материалов. Двадцатый век принес огромный размах приспособлений и правил, что привело к большим изменениям в лечении ран. Современные принципы и правила по уходу за ранами обеспечивают кроме комфорта для пациента соответствующие условия для заживления ран и облегчают организацию лечения сестрами по уходу [6]. К современным тенденциям по лечению декубитов относятся дебридмент декубитов, современные перевязочные материалы, вакуумная терапия, ларвальная терапия, лечение светом, лечение стволовыми клетками.

\section{Дебридмент декубитов}

Дебридмент - это хирургическое устранение инородного материала и контаминованных или некротических частей ткани и инфицированной части декубита. Цель дебридмента - улучшить в дальнейшем его заживление. Различают механический, аутолитический и химический дебридмент. Механический дебридмент это устранение инородного материала, особенно при расширенных некрозах, но его недостаток состоит в том, что он неселективный и его аппликацией можно повредить здоровую ткань. Классический механический дебридмент представляет устранение некротической ткани пинцетом или скальпелем. Современным способом механический дебридмент лечится при помощи гидротерапии, иригации высоким давлением, гидрохирургией и обследованием декубитов при помощи wet-to-dry. Аутолитический дебридмент используется, в основном, у пациентов, где механический дебридмент как более агрессивная форма лечения вызывает осложнения. Он реализуется при помощи терапевтических обвязываний, в том числе с использованием гидрогелев, алгинатов, гидроколоидов и плёночных покрытий. Он не рекомендован при расширенных некрозах, а в случае, когда необходимо быстрое устранение некроза, требует большего времени. Лечение более длительное, хотя и более простое. При химическом дебридменте используются химические составляющие, как кислота бензойная, кислота салициловая или $40 \%$ мочевина. Некроз разлагается при химическом процессе из-за низкого $\mathrm{pH}$. Минусом аппликаци является возможность раздражения кожи вокруг. Энзиматический дебридмент использует к распаду некроза энзимы протеазы, которые действуют локально и наносятся на поверхность декубита. Его использование не рекомендуется при инфицированных ранах [7]. Основной целью дебридмента является при помощи соответствующих материалов и правильной организации произвести трансформацию раны с хронического состояния, улучшить процесс заживления и устранить запах с пролежня. Главное - устранить некротические части декубита, чтобы был обеспечен процесс заживления декубита. Основой является то, что некротическое начало помогает росту бактерий в декубите.

\section{Современный перевязочный материал}

Современный перевязочный материал представляет собой значительный прогресс в лечении. Профессор Винтер почти пятьдесят лет назад изобрёл этот способ и тем самым дал ход позитивным изменениям в лечении декубитов. Благодаря современным материалам снижается количество некроз и инфекций в декубитах, сокращается время, необходимое на заживления ран, уменьшается работа персонала и улучшаются экономические показатели по уходу за больными $[7,8]$. Материал влажной терапии ставит перед собой цель удержать стабильную влажную среду, исполнять охранную функцию, минимализировать боль и травматизацию при замене, поглощать излишнюю секрецию в ране и он должен быть нетоксичным, финансово доступным и флексибильным [4]. К современным перевязочным материалам относится транспарантная плёнка, гидрогелевые и гидроколоидные перевязки, алгинаты, пены, перевязки, содержащие серебро и уголь. Выбранный материал должен быть действенным, выбор осуществляется по фазе заживления декубита, должен быть для пациента безопасным и экономичным. Материалы для влажного заживления декубитов:

- Плёночные покрытия - прозрачная водоохранная лента,используется при малых и плоских ранах, плюсом использования является визуальный контроль состояния раны.

- Гидрогели-гелевые покрытия, с высоким составом воды. Некоторые содержат действующее вещество. Их плюсом яляется снижение травматизации пациента и боли при перевязках, имеют охлаждающий эффект. Гидроколоидыvобеспечивают оптимальную среду для заживления декубитов, рекомендуются при ранах без инфекции.

- Алгинаты-средства, изготовленные из морских водорослей, с высокой абсорбцией, отлично устраняют эксудат из раны и налёт с низа раны. Имеют бактериостатическое и гемостатическое свойство, в ране изменяются на гель, которым покрывают низ раны.

- Повязки с содержанием серебра наносятся на декубиты с выраженной инфекцией или при подозрении на инфекцию. Повязки действуют на базе йонового серебра, имеют бактерицидное и фунгицидное действие, помогают рану вычистить и устранить из нее инфекцию.

- Повязки с содержанием активного угля поддерживают чистку и устранение запаха, имеют антисептическое свойство и поддерживают гемостаз [2]

\section{Вакуумная терапия}

Вакуумная терапия является неинвазивным современным методом заживления декубитов и ран, 
которая использует контролируемый вакуум, активное заключение раны к ее заживлению. Этот метод заживления ран называется NPWT negative pressure Wound Therapy или как VAC терапия vakuu massisted cloussure. Является терапевтически регулируемым лечением, где можно следить и проводить мониторинг давления, действующее на рану, с использованием в домашней среде и в медицинских учреждениях. Используется при лечении ран, дефектов мягких частей, декубитов и открытых переломов [9]. Механизм действия VAC терапии складывается из редукции бактериального нахождения в декубите, прямого стимулирования роста гранулированной ткани и улучшения перфузии, устранения опухоли и снижения эксудации из декубита.VAC терапией элиминируется появление синусов и туннелей при декубитах, можно создать соответствующее место для будущей кожной трансплантации [7]. Осложнениями при использовании терапии вакуумом являются возникновение опухоли, некроза в ране, если в основании раны находятся паренхиматозные органы, сосуды и нервы, контрадикцией может быть также остиомиелит, фустилы неясной этиологии. Перед нанесением негативного вакуума в декубит всегда необходимо исключить исхемию в области раны [10]. VAC терапевтическое устройство составляет черная (в лечении глубоких ран) или белая (в лечении поверхностных ран) пеновая губка, катетр и подставка облегчающие обмен покрытия и обеспечивающие безопасность для пациента, установка с дисплеем, дающим возможность установить вакуум и канистр для сбора секрета из раны [11]. Вакуумная терапия имеет огромное 3 начение для комфорта пациента, система содержит фильтрацию, которая устраняет запах из раны, снижением количества обмена покрытия минимализируется страх, боль от перевязок [12]. Задача медсестры при обследовании пациента при помощи вакуумной терапии состоит в том, чтобы: следить за общим состоянием пациента, контролировать ход лечения, следить за местом применения VAC системы, контролировать работу системы и её функциональность, следить за выделением секрета и его характером, о чём сестра ведёт запись в документации пациента [13].

\section{Личиночная терапия}

Личиночная терапия или maggot terapia - лечение ран и декубитов при помощи личинок Lucillia sericata. Личинки по многим исследованиям являются одним из наиболее действенных способов, особенно при лечении ран, колонизированных золотым стафилококком. Лечение личинками - метод, используемый в энзиматической и хирургической некректомии. Личинки питаются некротической тканью и вместе с этим выделяют энзимы, которые разделяют умершую ткань, что ведет к некроктолизу. Этот метод всё же имеет побочные действия при ранах, которые с фистулами и вблизи органов, при ранах вблизи больших сосудов, нервов и при склонности к кровотечениям [14].

Maggot Debridement или терапия личинками является намеренной апликацией медицинских личинок в раны, с целью дезинфекции этих ран и в заключительной фазе их заживления. Применяется как альтернатива хирургического вмешательства с лучшими результатами заживления ран. В Словацкой ресублике используется с 2004 года, причем в 2011 году началась бесплатная доставка стерильных личинок в медицинских целях. Личиночная терапия известна тем,что чистит рану быстро и без излишней перегрузки и повреждений здоровой ткани. Maggot терапия не дает никаких негативных последствий или осложнений. Личиночная терапия приносит положительный эффект: дебридмент, дезинфекцию и улучшение заживления. В последнее время предполагается и следующий механизм действия-ингибиция и ликвидация биофильмов разных бактерий [15].

На практике используются три основные техники нанесения личинок на рану: ретенционная клетка техника, которая была представлена Р.А.Шерманом, при помощи нового способа нанесения «ретенционной клетки» c использованием клеящей массы на базе поливинилюалкоголя и нанесения личинок в биопакетах [16]. Нанесение личинок на рану проводит врач при помощи медсестры, нежелательные действия при этой технике минимальнык. Скорее можно говорить о субъективных ощущениях как покалывание, жжение, небольшая боль. Нанесение личинок происходит в стерильных условиях. Вокруг раны или декубита натирается специальная паста,стерильным шприцом в рану попадает три миллилитра физиологического нраствора. Личинки, приложенные на нейлоновую сетку наносятся на рану и перекрываются стерильными квадратами. Перевязка осуществляется раз в 3-4 дня. Всегда необходимо вести учёт, сколько личинок нанесено. При личиночной терапии пациент может иметь повышенную температуру, о чем должен быть информирован сестрой по уходу [7].

\section{Лечение светом}

Одним из современных лечебных методов в решении проблем декубитов является лечение светом. Лечение светом или фототерапия это метод, который использует в лечении декубитов световые продукты. Действие фототерапии имеет противовоспалительный эффект и уменьшение боли. При лечении декубитов фототерапией быстрее заживают декубиты [17]. Фототерапия представляет метод, использующий поляризованный свет, то есть лазер и биолампы. Эффект биолампы похож на эффект лазеров, но со стороны терапевтического использования и нужд обеспечения норм безопасности и подготовки персонала на практике больше используются биолампы. По этой причине были развиты технологии поляризованного-красного света, которые развиты ЛЕД диодами и благодаря этому могут проникнуть глубже в ткани и получить более результативный биологический ответ на лечение. Красный поляризованный свет имеет подобный эффект как лазер, безопасен и его можно использовать в домашней обстановке. Имеет отличные результат на заживление ран и как профилактика ран различной этиологии и характера. Плюсами лечения светом является 
возможность местного использования, безопасность и безболезненность, высокий лечебный эффект и выгодная цена. К специфическим эффектам лазеротерапии относим анальгетический, антифлогистический и биостимуляционный эффект [7]. Терапия светом рекомендована не только в лечении, но и профилактике декубитов. Рекомендовано для рофилактики использовать 3-4 раза в день хотя бы на 4 минуты. Когда настанет изменение кожного покрова, этот интервал можно увеличить в 50-100 раз [18].

\section{Лечение стволовыми клетками}

Нарушенное заживление ран сопровождается эксцессивной инфильтрацией полиморфонуклеарных лейкоцитов, недостаточной выработкой гранулированной ткани, дефицитом коллагена и экспрессией факторов роста. Стволовые клетки позволяют обновлять некоторые структуры и реконструировать поврежденную ткань, потому что они ответственны за орьентирование и их дифференцированность на специфические клетки различных тканей. Проведённые клинические исследования как и экспериментальные исследования подтверждают, что стволовые клетки костной ткани поддерживают лечение хронических ран, включая декубиты. Современные исследования подтвердили, что самое эффективное - поместить клетки в ткани так,чтобы они достигли наивысшей концентрации в ране $[19,20]$. В 2005 году прошли первые попытки использования стволовых клеток в лечении декубитов. Эту возможность принесли иностранные исследователи, которые искали возможность лечения хронических декубитов после использования всех других возможных доступных способов [21].

\section{Заключение}

Современные средства в лечении декубитов возникли на основании новых знаний о фазовом заживлении ран. Основным принципом лечения является создание и удержание влажной среды,стабильной температуры,возможность замены водного пара и газов,препятствие секундарной инфекции и абсорбция излишнего эксудата. Следующим плюсом современных методов является минимализация риска сенсибилизации и иритации, увеличение интервалов между перевязками и легкое устранение покрытия, которое минимализирует травматизацию раны при отдельных перевязках. Некоторые материалы имеют анальгетические свойства и одновременно устраняют запах из раны. Комплексное отношение к пациентам может снизить страдания пациента, но и сократить расходы, связанные с долгосрочным лечением декубитов [7]. Широкий спектр изделий для современного обследования и лечения декубитов позволяет найти индивидувльный подход к каждому пациенту. Важен мониторинг, контроль, нахождение пациентов из групп риска,оценивание состояния кожи и предотвращение причин возникновения пролежней. Сестра по уходу должна соблюдать последовательность и соблюдать Национальный процессуальный стандарт. Обследование декубитов можно реализовать только с образованными и подготовленными медицинскими работниками [22].

\section{References}

1. Opršalová, G. Hojenie dekubitov. In Revue 1. ISSN 1336-202X, 2014. s. 27-28a.

2. Vytejčková, R. et al. Ošetřovatelské postupy v péči o nemocné III. Praha: Grada, 2015. 303 s. ISBN: 978-80-24-7342-21-7.

3. Hien, P. et al. Moderne Geriatrie und Akutmedizin. Deutsch: Spriger medizin, 2013. 220 s. ISBN: 978-3-642-25602-8.

5. Králová, E., Kulašníková, Z. Možností prevencie a terapie dekubitov. In: Praktické lekárnictvo. 2013. ISSN: 1338-3132. r. 3, č. 2, s. 51-54.

6. Belovičová, M. Vybrané kapitoly z geriatrie. Bardejov: VŠZaSP sv. Alžbety Bratislava, 2019.80 str. ISBN: 978-80-8132-203-7.

7. Dobsonyová, A. et al. Tradičné a moderné prístupy ošetrovania rán. In: Ošetrovatel’stvo - tradície a perspektívy, zborník vedeckých prác z celoslovenskej konferencie s medzinárodnou účast’ou. Piešt’any: 2016. ISBN: 978-80-8132-151-1. s. 15-30.

8. Stryja, J. Repetitorium hojení ran. Semily: GEUM, 2011.ISBN: 978-80-87969-1822-2.

9. Takáč, P. Bioterapeutické metódy v praxi. Bratislava: Centrum vedecko-technických informácií, 2012.29 s. ISBN: neuvedené.

10. Čambal, M. et al. Možností debridementu v liečbe chronických rán. In: Slovenská chirurgia. 2012. ISSN: 1336-5975. r. 9, č. 4, s.124-129.

11. Kopal, J. Liečba rán pomocou riadeného podtlaku. In: Dermatologie pro praxi. 2010. ISSN:1803-5337. r. 4, č.4, s. 135-139.

12. Chladková, L. Moderní trendy hojení rán a defektu. In: Diagnóza v ošetrovatelství. 2009. ISSN: 1801-1349. r. 5, č. 6, s. 11-14.

13. Šimek, M. et al. 2013. Podtlaková léčba ran. Praha: Maxdorf, 2013. 231 s. ISBN: 978-80-7345-352-7.

14. Grunterová, T. Podtlaková terapia. In: Diagnóza v ošetrovatelstvi. 2013. ISSN: 1801-1349. r. 9, č. 1, s. 17-18.

15. Podrazilová, P. Maggot terapie aneb léčba larvami : Diagnóza v ošetrovatelstvi. 2009. ISSN: 1801-1349. r. 5, č. 1, s. $17-18$.

16. Gotrupp, F. et al. Maggot Debridement: An Alternative Method for Debridement In: Open Access Journal of Plastic Surgery. July 2011.Vol.11,290-302. [online]. Citované dňa [9.3.2019]. Dostupné na: <www.eplasty.com>.

17. Čambal, M. et al. 2013. Larválna terapia a chronicky nehojace sa rany In: Slovenská chirurgia. 2013. ISSN: 1336-5975. r. X, č. 1, s. 8-11. 
18. Pokorná, A. Mrázová, A. Kompendium hojení ran pro sestry. Praha: Grada, 2012. 191 s. ISBN: 978-80-024-7333-71-5.

19. Kapounová, G. Ošetřovatelství v intenzivní péči. Praha: Garda, 2007. 389s. ISBN: 978-80-247-1830-9.

20. Lakytová, L, Radoňák, J. 2013. Využitie kmeňových buniek kostnej drene pri hojení chronických rán - rewiev. In: Slovenská chirurgia. 2013. ISSN: 1336-5976. r. 10, č. 2, s. 48-51.

21. Szarvaš Matáková, J. Moderné trendy liečby dekubitov z pohl’adu sestier. (bakalárska práca). Bratislava: Vysoká škola zdravotníctva a sociálne práce sv. Alžbety v Bratislave, 2019, s. 57.

22. Pejznochová, I. Lokální ošetřování ran a defektů na kůži. Praha: Grada, 2010. 80 s. ISBN 978-80-247-2682-3

23. Osacká, P. a kol. Techniky a postupy v ošetrovatel'stve [CD-ROM]. 1. vyd. Bratislava: JLF UK, 2007.505 s. ISBN 978-80-88866-48-0.

Дата надходження рукопису до редакції: 22.06 .2020 р.

Пролежни являются наиболее проблематичным осложнением в здравоохранении. Появление и количество пролежней являются отражением качественного медицинского ухода. Сестра по уходу является членом мультидисциплинарного коллектива и при образовании пролежней играет важную роль, поэтому она должна обладать адекватной информацией о современных возможностях в лечении пролежней и использовать эти возможности в практической деятельности.

Результаты. В этой статье мы обращаем внимание на действия сестры по уходу в предупреждении пролежней. Акцентируем внимание на отдельные тренды в лечении пролежней как, например, современный перевязочный материал, вакуумная терапия, личиночная терапия, лечене светом, лечение стволовыми клетками.

Заключение. Широкий спектр продуктов в современном лечении и обследовании пролежней позволяет найти максимально индивидуальный подход к каждому пациенту. Важны: мониторинг, контроль и разыскивание пациентов, которые находятся в группе риска, определение состояния кожи поврежденных мест, определение причин возникновения пролежней, образованные и хорошо подготовленные сестры по уходу.

Ключевые слова: пролежни, современные тренды в лечении, сестра по уходу.

Пролежні $\epsilon$ найбільш проблематичним ускладненням в охороні здоров'я. Поява і кількість пролежнів $\epsilon$ відображенням якісного медичного догляду. Сестра по догляду є членом мультидисциплінарного колективу і при утворенні пролежнів грає важливу роль, тому вона повинна володіти адекватної інформацією про сучасні можливості в лікуванні пролежнів і використовувати ці можливості в практичній діяльності.

Результати. У цій статті ми звертаємо увагу на дії сестри по догляду в попередженні пролежнів. Акцентуємо увагу на окремі тренди в лікуванні пролежнів як, наприклад, сучасний перев'язувальний матеріал, вакуумна терапія, личиночная терапія, лікування світлом, лікування стовбуровими клітинами.

Висновки. Широкий спектр продуктів в сучасному лікуванні і обстеженні пролежнів дозволяє знайти максимально індивідуальний підхід до кожного пацієнта. Важливі: моніторинг, контроль і розшукування пацієнтів, які знаходяться в групі ризику, визначення стану шкіри пошкоджених місць, визначення причин виникнення пролежнів, освічені й добре підготовлені сестри по догляду.

Ключові слова: пролежні, сучасні тренди в лікуванні, сестра по догляду.

Pressure ulcers are the most problematic complication in the provision of health care. The appearance and number of pressure ulcers reflect the quality of health care. The nurse is part of a multidisciplinary team and plays an important role in the development and prophylaxis of pressure ulcers. Therefore, she should have adequate information on current treatment options for pressure ulcers and use these options in her practice.

Results. In this article, we focus on the nurse's care of the patient's skin in the interest of prophylaxis of pressure ulcers. We emphasize our attention to trends in the treatment of pressure ulcers, such as modern dressing material, vacuum therapy, larval therapy, light therapy, stem cell therapy.

Conclusions. A wide range of products in the treatment of pressure ulcers allows us to find the most individualized approach to each patient. Important are: monitoring, control and search for patients at risk, evaluation of the condition of the skin and damaged areas, determination of the causes of pressure ulcers, trained and well-prepared nurses.

Key words: pressure ulcers, new trends in the wound healing, nurses.

\section{Відомості про автора}

Popovičová Mária - Assoc. Prof., PhDr., PhD., St. Elizabeth University of Health and Social Sciences, Bratislava - teacher, Field office in Michalovce a Prešov, Vysoká škola zdravotníctva a sociálnej práce sv. Alžbety Bratislava, pracovisko Michalovce. maria.popovic911@gmail.com. 